\title{
Simulasi Pengoperasian Motor Pompa Air Berbasis Programmable Logic Control
}

\author{
Elvy Sahnur Nasution ${ }^{1}$, M. Fitra ${ }^{1}$, Suhendra ${ }^{1}$, Arnawan Hasibuan ${ }^{1}$ \\ ${ }^{1}$ Fakultas Teknik, Universitas Muhammadiyah Sumatera Utara
}

\section{ARTICLE INFORMATION}

Received: December 10, 2020

Revised: December 29, 2020

Available online: December 31, 2020

\section{KEYWORDS}

PLC, Simulation, Water Pump Motor

\section{CORRESPONDENCE}

Name: Elvy Sahnur Nasution

E-mail: elvysahnur@umsu.ac.id

\section{A B S S T R A C $\mathbf{C}$}

Maintain the availability of clean water in a multy-storey building make the water pump motor oprate continuously which can cause motor damage quickly, because there is no replacement system change of operation of the clean water pump motor conventional outomatic control. PLC (Programmable Logic Control) type Schneider Smart Relay Zelio Logic can be an opration to overcome clean water pump motor operation system to replace convensional automated system in to PLCbased automated systems. Simulation of the operational of a clean water pump motor in a multi-storey build use PLC software type Schneider Zelio Soft2 type SR2B121BD operate 3 clean water pump motors alternately between the source pump motor and the transfer pump motor, measurement of operating time transfer pump motor 1 with transfer pump motor 2 and the design of the alaram system trip to avoid damage to the motor using alarm rirens. Operating of PLC-based outomatic water pump motor very helpful oprator to operate the clean water pump motorized, where the operation of a clean water pump motor can be changed trought software as needed.

\section{PENDAHULUAN}

Perkembangan kota-kota besar di Indonesia dari tahun ketahun semakin pesat sehingga banyak dibangun gedung- gedung bertingkat sebagai perkantoran, apartemen, perhotelan, rumah susun dan gedung bertingkat lainnya. Banyak persyaratan yang harus dipenuhi dalam membangun gedung bertingkat salah satunya persyaratan sanitasi dimana kualitas air bersih, sistem distribusi dan penampungan air harus sesuai pedoman dan persyaratan teknis yang berlaku.

Pendistribusian air bersih pada gedung bertingkat sangat memerlukan suatu instalasi pendistribusian yang mampu memenuhi kebutuhan air bersih secara merata keseluruh tempat pada gedung. Seperti di kota Medan khususnya pada gedung bertingkat di salah satu kampus yang mempunyai lima lantai. Gedung bertingkat seperti ini membuat penyaluran air bersih cukup sulit karena membutuhkan pompa untuk pengisian air bersih dari Bak bawah ke Tandon yang letaknya di atas gedung. Jika air dalam Tandon sudah penuh, selanjutnya air dialirkan dengan memanfaatkan gaya gravitasi.
Menjaga ketersediaan air bersih di gedung bertingkat membuat motor pompa air beroperasi secara terusmenerus yang bisa menyebabkan motor cepat mengalami kerusakan, karena tidak adanya sistem pergantian pengoperasian antara motor pompa sumber dengan motor pompa transfer dan sistem waktu pengoperaian.

Sistem pengoperasian pompa air bersih digedung bertingkat diperlukan teknologi yang terbaru dengan menggunakan PLC (programmable logic control) untuk menggantikan sistem otomatis konvensional. Penggunaan PLC jenis Schneider Smart Relay Zelio Logic bisa menjadi pilihan untuk mengatasi waktu pengopersian pompa air bersih. Dengan software PLC kita dapat mengatur dan mengubah waktu pengoperasian motor pompa air bersih.

Berdasarkan hal di atas maka penulis tertarik untuk membahas metode "Simulasi pengoperasian motor pompa air berbasis PLC", untuk mengatur waktu pengoperasian terhadap tiga motor pompa air bersih agar terhindar dari kerusakan. 


\section{METODELOGI}

\section{Lokasi dan Tempat Penelitian}

Penelitian dilaksanakan pada bulan November tahun 2020, tempat penelitian adalah sistem pendistribusian air bersih pada gedung Rusunawa Universitas Muhammadiyah Sumatera Utara

\section{Peralatan}

Peralatan penunjang yang digunkan untuk membuat alat simulasi pengoperasian pompai air pada gedung bertingkat yaitu :

1. Mesin bor listrik digunakan untuk membuat lubang dan memasang skrup pada rangka panel.

2. Alat Tangan (Obeng, Tang Potong, dan lain sebagainya)

3. Alat Ukur (Tespen, Multitester, Tang Ampere).

\section{Bahan-bahan Penelitian}

Bahan-bahan yang digunakan untuk pembuatan alat simulasi pengopeasian pompa air berish adalah:

1. Laptop Lenovo ThinkPad L512, Intel (R) Core (TM) i3 CPU, M380 2.53GHz, Ram 2GB, OS (Operating System) Windows 7 Ultimate 64 it.

2. PLC Schneider Zelio Logic SR2 B121BD berfungsi sebagai sistem yang akan mengatur pengoperasian motor pompa air bersih.

3. Box Panel Listrik untuk pengamanan dan kerapihan suatu instalisi listrik.

4. MCB 1 Fasa melindungi rangkain dari arus yang berlebihan dengan cara memutuskan arus secara otomatis saat melewati batas tertentu.

5. Catu Daya DC24V/10A sebagai sumber tegangan untuk rangakian PLC.

6. Relay Omron MKP2P-1 berfungsi untuk menghubungkan atau memutus suatu arus listrik dengan memberi tegangan atau memutus tegangan pada kaki pengendali.

7. Kabel Data untuk mentransfer program dari laptop ke PLC.

8. Pompa aquarium recent aa1200 untuk simulasi pengisian bak air.

9. Push Button sebagai pemutus atau penyambung arus listrik daris sember listrik ke beban.

\section{Tahapan penelitian}

Tahapan penelitian yang dilakukan adalah :

1. Mengidentifikasi permasalahan sistem pendistribusian air di gedung Rusunawa

2. Mengambil mengumpulkan data sistem pendistribusian air

3. Merancang peralatan pengoperasian pendistribusian air

4. Merancang program yang akan digunakan untuk mensimulasikan pendistribusian air

5. Melakukan uji coba pada peralatan dan program

\section{Diagram Penelitian}

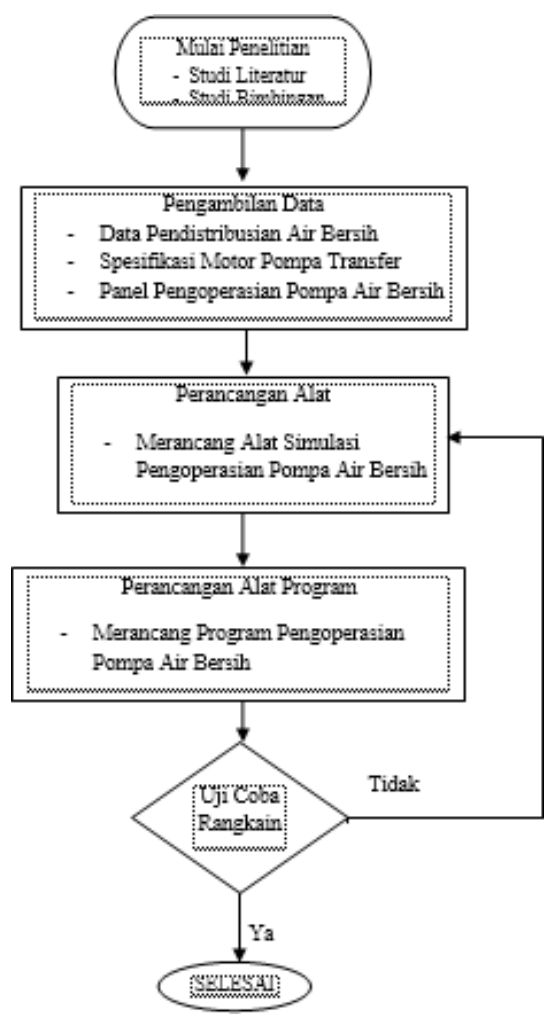

Gambar 1. Diagram Alir Penelitian

\section{Rangkaian Penelitian}

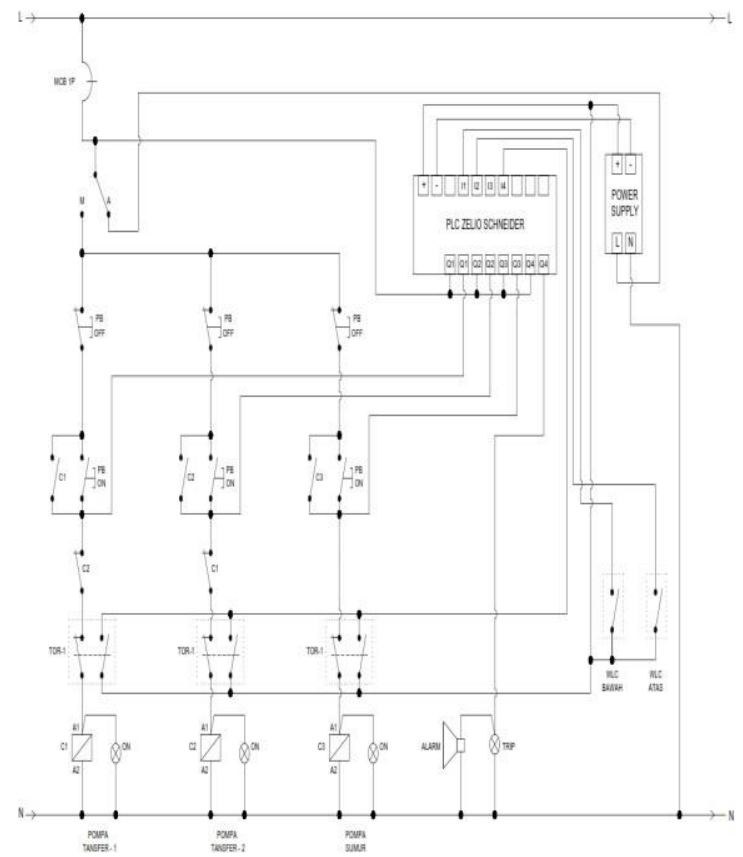

Gambar 2. Diagram wiring otomatis berbasis PLC SR2B121BD 


\section{HASIL DAN PEMBAHASAN}

\section{Pengoperasian Pompa Air Bersih Konvensional}

Sebelum menggunakan komponen PLC, pengoperasian motor pompa air bersih Gedung bertingkat masih menggunakan sistem otomatis konvesnsional yang tidak ada pengaturan waktu pengoperasian pompa transfer 1 dan pompa transfer 2. Sistem kerja otomatis konvesional pengisian air bak bawah dan tandon atas ketika sensor WLC mencapai batas minimum volume bak air maka saklar WLC NO (Normaly Open) menjadi NC (Normaly Close) dan motor pompa air akan ON, Setelah volume bak air mencapai batas maksimum saklar WLC akan kembali ke NO. Sistem pengoperasian motor pompa air otomatis konvensional akan standby beroperasi secara terus menerus dalam waktu 24 jam. Untuk menonaktifkan pengoperasian motor pompa air bersih pada malam hari memerlukan operator, sistem pengoperasian ini dinilai sangat tidak efisien, karena membutuhkan operator untuk menonaktifkan pengoperasian pompa air bersih dan diprediksi dapat berpeluang menyebabkan kesalahankesalahan seperti human error.

\section{Pengopersian Pompa Air Berbasis PLC}

Schneider Zelio Logic SR2B121BD memiliki peran sangat utama dalam mengatur waktu pengoperasian motor pompa air bersih. Sistem kerja pengoperasian air otomatis berbasis PLC apabila WLC (Water Level Control) telah mencapai batas minimun volume air pada bak maka WLC akan memberi sinyal input ke PLC memberi sinyal perintah menghidupkan pompa air untuk melakukan pengisian, setelah volume air pada bak mencapai batas maksimum maka WLC akan memberi sinyal input ke PLC memberikan sinyal perintah mematikan pompa air menghentikan pengisian pada bak bawah atau tandon atas.

Untuk pengisian air dari bak bawah ke tandon atas menggunakan dua motor pompa air transfer sehingga motor pompa air transfer dapat beroperasi secara bergantian. Pada sistem ini dibuat waktu pengoperasian motor transfer 1 akan $O N$ standby beroperasi pada pukul $04.00 \mathrm{~s} / \mathrm{d} 13.00 \mathrm{WIB}$, sedangkan motor transfer 2 akan OFF. Selanjutnya motor transfer 2 akan ON standby beroperasi pada pukul $13.30 \mathrm{~s} / \mathrm{d} 23.00 \mathrm{WIB}$, sedangkan motor pompa 1 akan $O F F$. Saat pukul 23.01 s/d 04.39 motor transfer 1 dan motor transfer 2 akan $O F F$ ini dilakukan karena tidak adanya operator yang berada di Rusunawa UMSU, pengaturan waktu pengoperasian pompa transfer dapat diubah sesuai dengan kebutuhan. Berikut ini tabel waktu pengoperasian pompa air transfer.
Tabel 1. Waktu Pengoperasian Motor Pompa Air Transfer

\begin{tabular}{cccc}
\hline No & $\begin{array}{c}\text { Waktu pengoperasian } \\
\text { pompa }\end{array}$ & $\begin{array}{c}\text { Pompa } \\
\text { transfer 1 }\end{array}$ & $\begin{array}{c}\text { Pompa } \\
\text { transfer 2 }\end{array}$ \\
\hline 1 & $04.00 \mathrm{~s} / \mathrm{d} 13.00 \mathrm{WIB}$ & ON & OFF \\
2 & $13.00 \mathrm{~s} / \mathrm{d} 23.00 \mathrm{WIB}$ & OFF & ON \\
3 & $23.01 \mathrm{~s} / \mathrm{d}$ 03.59 WIB & OFF & OFF \\
\hline
\end{tabular}

Pengoperasian pompa air transfer dan pompa air tanam di rancang tidak bisa hidup secara bersamaan, yaitu ketika sensor bak bawah NO menjadi NC maka secara otomatis saklar bak bawah akan memutus rangkaian sensor tandon atas sehingga pompa transfer tidak dapat beroperasi meskipun sensor tandon atas dalam kondisi NC memberikan sinyal pengisian bak, Pengaturan ini di rancang untuk menghindari kerusakan pada motor pompa transfer.

Tabel 2. Pengaturan Pengoperasian Pompa Rendam dan Pompa Transfer

\begin{tabular}{ccc}
\hline No & $\begin{array}{c}\text { Motor Pompa } \\
\text { Rendam }\end{array}$ & $\begin{array}{c}\text { Motor Pompa Transfer 1 } \\
\text { dan } 2\end{array}$ \\
\hline 1 & ON & OFF \\
2 & OFF & ON \\
\hline
\end{tabular}

\section{Pengujian Sistem}

Pengujian sistem dengan cara simulasi dengan software di lakukan untuk mengetahui pengoperasian motor pompa air sesuai yang dinginkan sebelum di terapkan pada alat.

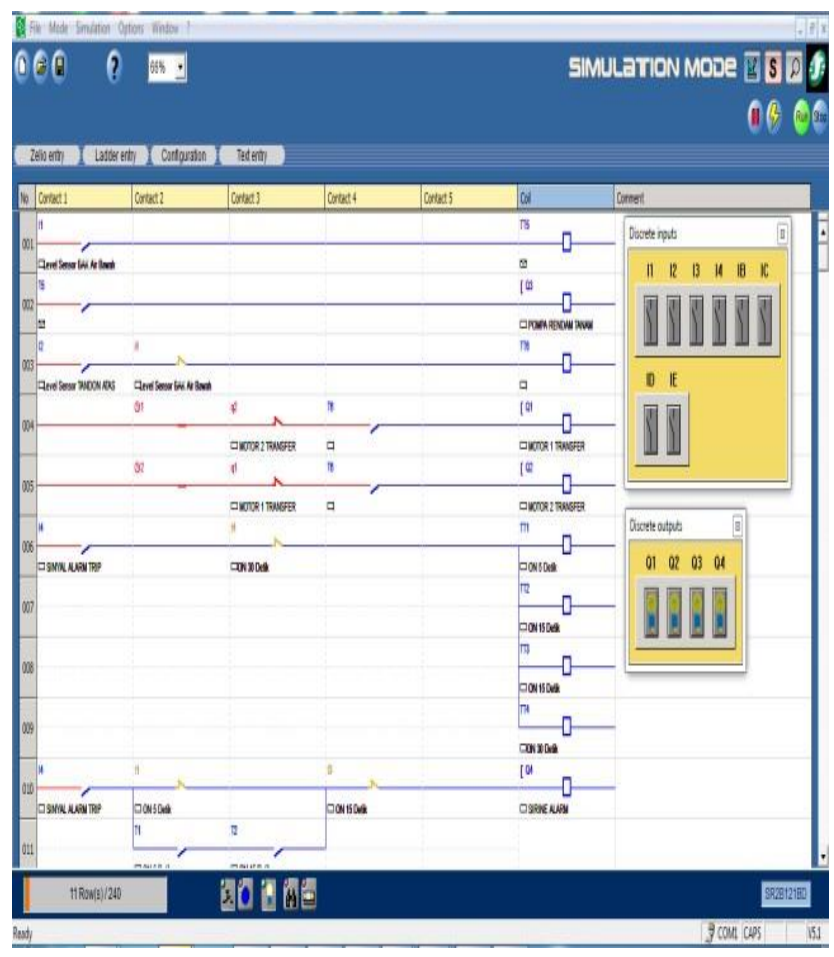

Gambar 1. Rangkaian dalam keadaan Run siap untuk di simulasikan 
Tabel 3 Keterangan Kondisi Jalur Rangkaian

\begin{tabular}{|c|c|c|}
\hline No & Simbol & Keterangan \\
\hline 1 & & $\begin{array}{c}\text { Jalur rangkaian dalam kondisi } \\
\text { ON }\end{array}$ \\
\hline 2 & & $\begin{array}{c}\text { Jalur rangkaian dalam kondisi } \\
\text { OFF }\end{array}$ \\
\hline 3 & - & $\begin{array}{c}\text { Jalur rangkaian dalam kondisi } \\
\text { NC }\end{array}$ \\
\hline 4 & & $\begin{array}{c}\text { Jalur rangkaian dalam kondisi } \\
\text { NO }\end{array}$ \\
\hline
\end{tabular}

Simulasi dimulai dengan menekan I1 saklar bak bawah NO menjadi NC sehingga T5 akan menghidupkan motor dalam waktu 5 detik.

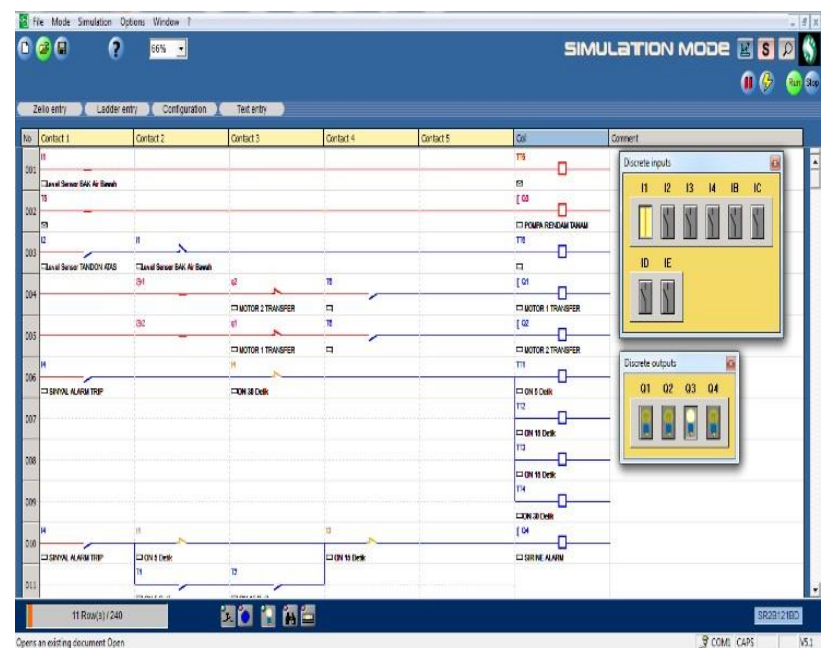

Gambar 2. Pengoperasian Motor Pompa Rendam Tanam

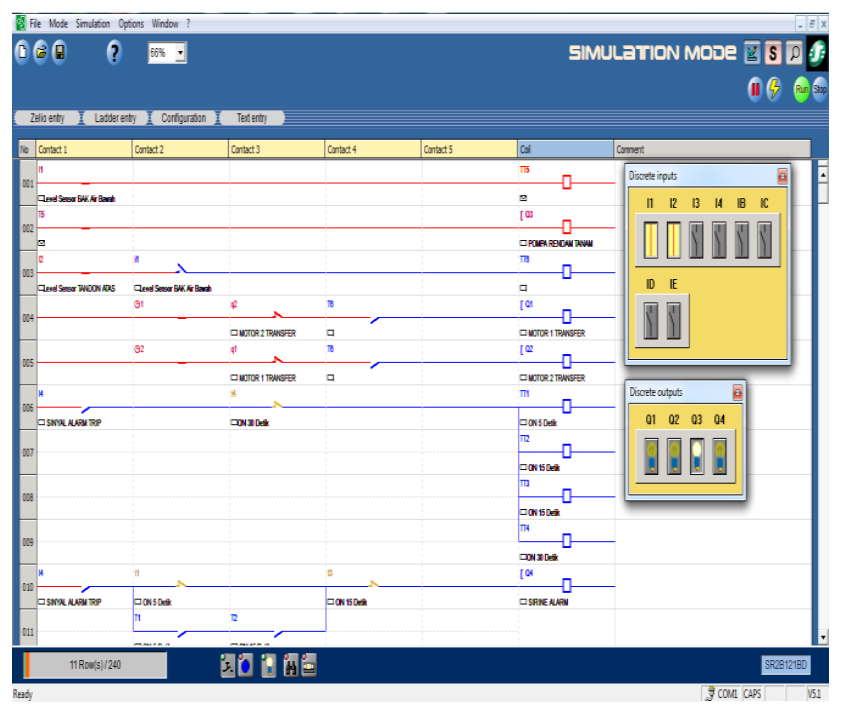

Gambar 3. Sensor Tandon NC

Saklar I2 tidak dapat mengoperasikan pompa transfer disebabkan saklar I1 masih dalam keadaan NC. Setelah saklar I1 menjadi NO pada jalur 1 otomatis akan menjadi NC pada jalur 2. Saklar I1 mengunci saklar I2 ini di rancang untuk mengatur pengoperasian motor pompa tanam dan motor pompa transfer.

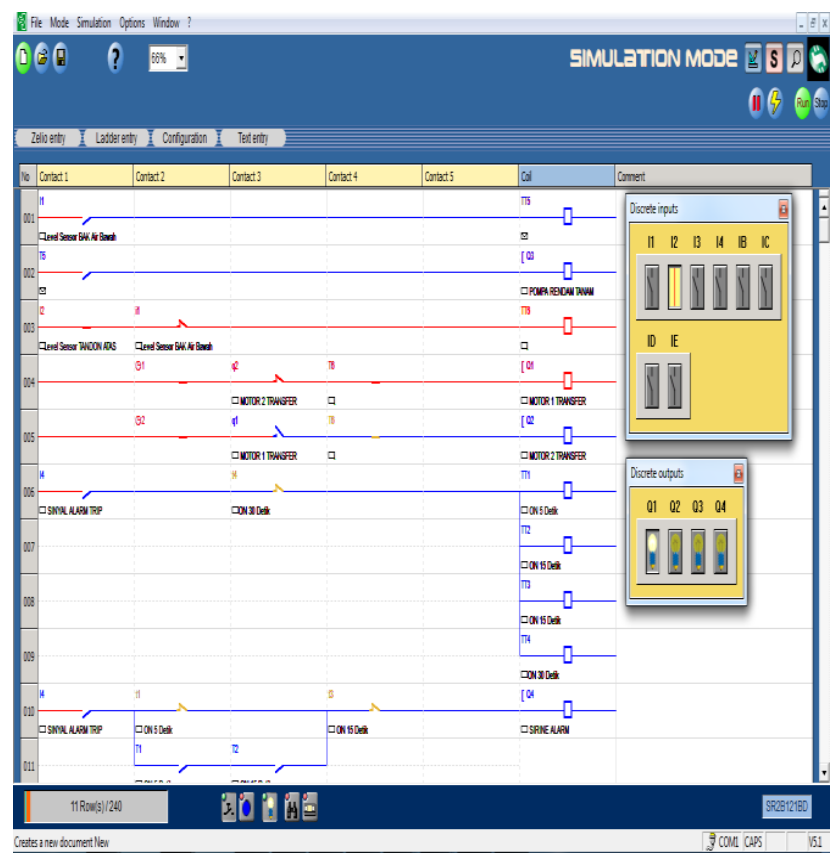

Gambar 4. Pengoperasian Motor Pompa Transfer

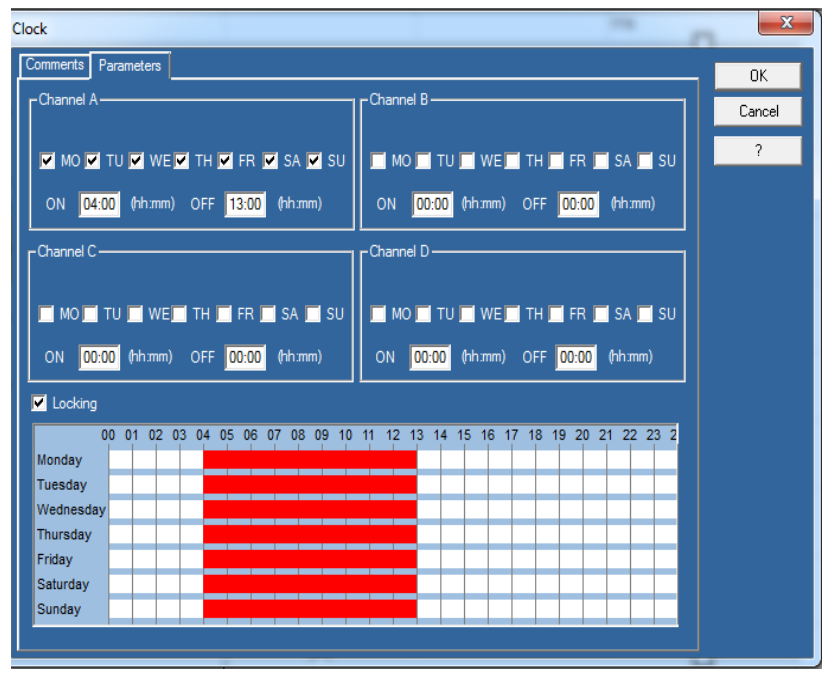

Gambar 5. Jadwal Pengoperasian Pompa Transfer 1

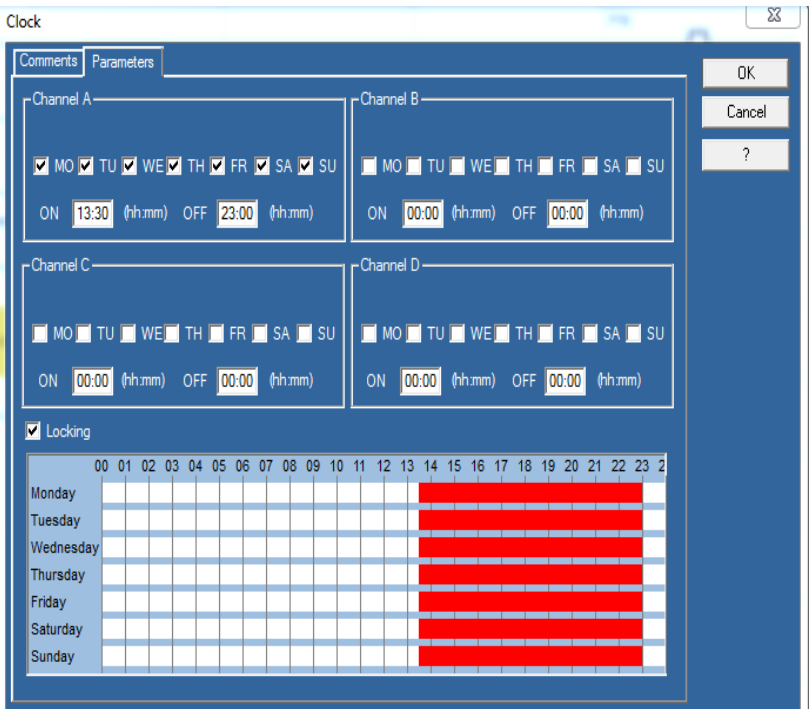

Gambar 6. Jadwal Pengoperasian Pompa Transfer 2 


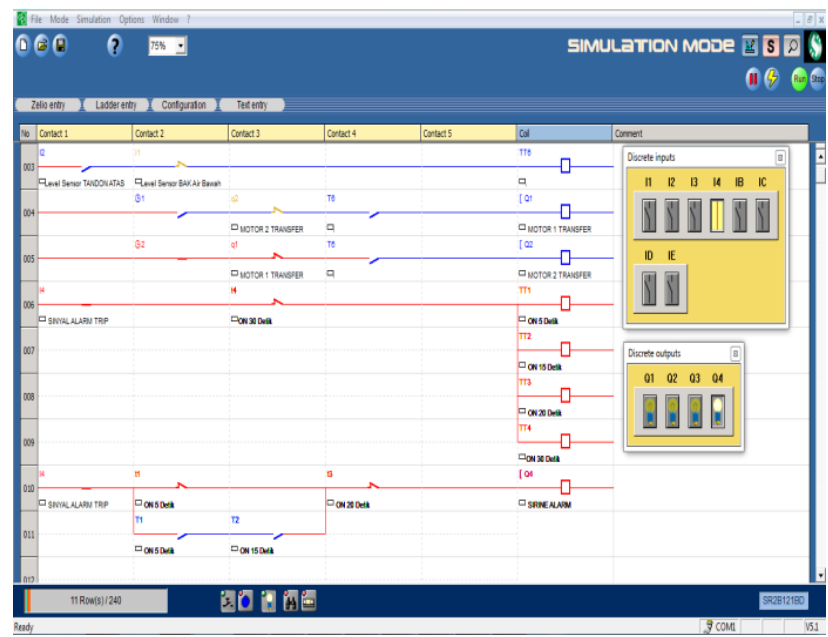

Gambar 7. Sistem Proteksi

Perancangan sistem proteksi untuk pengaman arus pada rangkaian motor, Apabila terjadi ganguan pada motor maka overload memutus jalur ke motor dan akan memberi sinyal input I4 ke PLC. I4 terhubung dengan saklar NC t4 yang telah diberi waktu sirine alarm 30 detik.

Tabel 4 Pembagian Waktu Sirine Alarm

\begin{tabular}{|c|c|c|c|c|c|c|c|}
\hline No & Function & Label & |Type & Preset & Curent & Lock & Comment \\
\hline 001 & & $\mathrm{T1}$ & A: Active, control held down & $T 1=005.0 \mathrm{~S}$ & $T 1=005.0 \mathrm{~S}$ & № & ON 5 Detik \\
\hline 002 & Timer & $\mathrm{T} 2$ & A: Active, control held down & $T 2=015.0 \mathrm{~S}$ & $T 2=015.0 \mathrm{~S}$ & № & ON 15 Detik \\
\hline 003 & Timer & $\mathrm{T}_{3}$ & A: Active, control held down & $T 3=020.0 \mathrm{~S}$ & $T 3=020.0 \mathrm{~S}$ & № & ON 20 Detik \\
\hline 004 & Timer & T4 & A: Active, control held down & $T 4=030.0 \mathrm{~S}$ & $T 4=029.9 \mathrm{~S}$ & № & ON 30 Detik \\
\hline
\end{tabular}

\section{KESIMPULAN}

1. Pengoperasian motor pompa air bersih pada gedung bertingkat dengan sistem otomatis konvensional tidak efisen karena membutuhkan operator untuk menonaktifkan pengoperasian pompa air bersih yang bisa menyebabkan kesalahan (human error) atau kerusakan pada motor pompa air dan komponen lainnya.

2. Pengoperasian motor pompa air otomatis berbasis PLC sangat membantu operator untuk megoperasikan pompa air bersih, pengaturan waktu pengoperasian motor dapat di diubah melalui software sesuai dengan kebutuhan pengoperasian motor tanpa mengganti komponen atau mengubah rangkaian hadware.

\section{DAFTAR PUSTAKA}

[1] M. Suhendar et al., "Rancangan Smart Relay Zelio Pada Pengoperasian Pompa Air Bersih Gedung Bertingkat," vol. 4, no. 2, pp. 29-37, 2017.

[2] A. Nuwolo, A. Kusmantoro, J. T. Elektro, and F. Teknik, "IbM Brik Dan Elektronika di SMK Pelita."
[3] R. P. Andi Adriansyah, "Jurnal Teknologi Elektro, Universitas Mercu Buana ISSN : 2086 - 9479,” vol. 4, no. 1, 2013.

[4] D. T. Mesin, F. Teknik, U. N. Surabaya, J. T. Mesin, F. Teknik, and U. N. Surabaya, "Pemrograman Trainer Control Level Air Berbasis PLC Wicaksono Windy Saputro Agung Prijo Budijono," vol. 01, pp. 74-79, 2013.

[5] B. Liputo et al., "Sistem kontrol penyiram bunga pada pot menggunakan smart rellay pada bangunan rumah bertingkat," vol. 2, 2017.

[6] U. Wiharja, "Rancangan Sistem Pengendali Motor Induksi Tiga Fasa Dengan Water Level Control ( WLC )," pp. 580-585, 2018.

[7] D. Wifi, J. E. T. Pioh, L. S. Patras, and I. F. Lisi, "Pengendalian Motor Listrik Dari Jarak Jauh Dengan Menggunakan Software Zelio Soft 2," vol. 5, no. 2, 2016.

[8] S. K. Subramaniam, S. H. Husin, S. A. Anas, and A. H. Hamidon, "Multiple Method Switching System for Electrical Appliances using Programmable Logic Controller," vol. 4, no. 6, pp. 243-252, 2009.

[9] L. Assafat, "Perancangan sistem pengolahan air bersih berbasis plc omron cpm 2a," Tek. - Unisfat, vol. 5, no. 1, pp. 42-53, 2009.

[10] P. Bunga, "Perancangan Sistem Pengendalian Beban Dari Jarak Jauh Menggunakan Smart Relay," EJournal Tek. Elektro dan Komput., vol. 5, no. 5, p. 11, 2015.

[11] S. Syahreza, "Rancang Bangun Pengendali Otomatik Ketinggian Fluida dan Temperatur Menggunakan Programmable Logic Controller ( PLC )," Rekayasa Elektr., vol. 9, no. 1, pp. 36-42, 2010.

[12] A. Abdullah and I. Hasyim Rosma, "Proteksi Panas lebih Pada Generator Berbasiskan Smart Relay," J. Online Mhs. Bid. Tek. dan Sains, vol. 5, no. 1, pp. 16, 2017.

[13] Bandura, C. Barbaranelli, G. V Caprara, and C. Pastorelli, "Universitas Sumatera Utara," Child Dev., vol. 72, no. 1, pp. 187-206, 2008.

[14] A. Mashar, Teknik Pemanfaatan TENAGA LISTRIK. Bandung, 2007.

[15] M. Elektrika and L. Belakang, "Motor Induksi Tiga Fasa Menggunakan,” vol. 9, no. 2, 2016.

[16] M. Abdilah, Pengendali Motor Listrik Dengan PLC, vol. 84. Pontianak, 2015. 